\title{
A “CRISE” MUNDIAL DA ÁGUA VISTA NUMA PERSPECTIVA DA GEOGRAFIA POLÍTICA
}

Carlos Alexandre Leao Bordalo

Resumo: Neste início de século a Organização das Nações Unidas já realizou três Fóruns Mundiais da Água (Kyoto, 2003; Cidade do México, 2006 e Istambul, 2009) onde foram travadas guerras de paradigmas. O da água como direito humano universal versus a água como mercadoria, e o de uma crise eminente para no abastecimento de água doce ainda neste século. Esses são temas que devem ser refletidos por todos, e aqui apresentamos numa perspectiva da geografia política, uma reflexão sobre que crise mundial da água é essa? Onde veremos que ela não é uma crise de disponibilidade de água doce, mas sim na crise do desigual acesso à água, bem como nas diferentes formas de utilização e consumo, bem dispares entre os países ricos e pobres.

Palavras Chave: Geografia Política, Geografia Política da Água, Geopolítica da Água, Hidropolítica, Hidrogeografia.

\section{THE GLOBAL WATER “CRI SIS” SEEN BY PERSPECTI VE OF THE POLITI CAL GEOGRAPHY}

Abstract: In this beginning century the Unit Nation Organization has held three Water World Forum (Kyoto, 2003, Mexico City, 2006, Istanbul, 2009) where wars were fought in paradigms. The water as a universal human right versus water as a commodity, and an imminent crisis for the supply of fresh water even in this century. These are issues that should be analyzed by all, and here we present a perspective of political geography, a reflection about the global water crisis that is? Where we will see that it is not a crisis of availability of fresh water, but the crisis of unequal access to water, as well as, in different forms of use and consumption, such as the disparately between rich and poor countries.

Key words: Politics Geography, Water's Politics Geography, Water's Geopolitics, Water's Political, Hidrogeography.

\section{I ntrodução}

Neste início de século a Organização das Nações Unidas já realizou três Fóruns Mundiais da Água (Kyoto, 2003; Cidade do México, 2006 e Istambul, 2009) onde foram travadas guerras de paradigmas. O da água como direito humano universal versus a água como mercadoria, e o de uma crise eminente para no abastecimento de água doce ainda neste século.
Diante do atual dimensionamento e mapeamento da disponibilidade quantitativa e qualitativa da água doce no mundo, a ONU apresentou em março 2003 em Kyoto, Japão, durante a realização do Terceiro Foro Mundial sobre a Água o "Ano Internacional da Água Doce", a publicação do primeiro Informe das Nações Unidas sobre o Desenvolvimento dos Recursos Hídricos no Mundo (WWDR) "Água para todos, Água para vida". Apresentando a

Universidade Federal do Pará - UFPA. Email: carlosbordalo@oi.com.br 
nível mundial um dos mais importantes debates deste novo século, que nortearam a sobrevivência da humanidade e do próprio planeta, diante da "crise" mundial da água doce.

$$
\text { O referido informe (WWDR) }
$$

apresenta o primeiro resultado do estudo organizado pela ONU desde o ano de 2000 através do Programa Mundial de Avaliação dos Recursos Hídricos (WWAP), do qual participam conjuntamente mais de 23 agências da própria ONU e secretariado pela UNESCO. Com os resultados obtidos a partir dos dados da Organização Mundial de Meteorologia e de outras instituições, e cruzados com os dados fornecidos nos indicadores sociais, econômicos e demográficos, pode-se, então construir cenários sobre a oferta e demanda mundial por recursos hídricos para a segunda metade deste século.

O presente artigo tem como objetivos entender numa perspectiva da geografia política como se apresenta nos relatórios oficiais da ONU o cenário de uma "crise" mundial da água doce para o século $X X I$ e quais as reais explicações para essa "crise" que passa a ser entendida como uma verdadeira hidropolítica.

Na geografia contemporânea, o debate acerca da crise mundial da água doce ainda é muito recente e restrito. Ainda são poucos os geógrafos famosos que se envolvem com o tema água. Visto que, ao longo de décadas, a água vinha sendo tratada equivocadamente como um recurso natural abundante e inesgotável. Visão errônea esta que ocultou por muitos anos, os verdadeiros valores: sanitário, cultural, social, econômico e geopolítico que a água possui e possuirá ainda mais neste século, pois para muitos ela já é considerara o "ouro azul".

Não pretendemos neste artigo, fazer como Costa (2008), um belíssimo retorno aos fundamentos da Geografia Política Clássica expressa nas obras de Ratzel e Vallaux, e tão pouco refletirmos em relação ao rico debate referente ao entendimento da Geografia Política como disciplina científica, outrora presente em Browman, Hartshorne, Stephen Jones, L Carlson, e Yves Lacoste.

Neste artigo, mostraremos como que alguns geógrafos estão pensando e escrevendo sobre esse tema "crise mundial da água", numa perspectiva da geografia política da água, da geopolítica da água ou até mesmo numa hidropolítica.

Essa preocupação sobre uma "crise" da água doce diante da expansão desenfreada no consumo também é apontada pelo geógrafo norte-americano Peter Gleick, professor do Pacific Institute for Studies in Development, Environment, and Security da Califórnia. Como conseqüência da lenta redefinição ou mudança no paradigma do planejamento e manejo dos recursos hídricos, nos países desenvolvidos. É que o problema do "risco" de escassez hídrica para o próximo milênio está relacionado à necessidade de uma mudança mais rápida de um novo paradigma que adote o manejo da água, voltado ao aumento da eficiência do sistema de abastecimento, bem como no tratamento e reutilização dos efluentes residenciais e industriais.

Gleick (1998) ressalta que no século XIX a revolução industrial e o elevado crescimento populacional foram responsáveis por uma dramática e extensa modificação no ciclo hidrológico, através da construção de grandes projetos de engenharia destinados 
ao controle de inundação em áreas de planícies, para geração de energia hidráulica e os voltados para irrigação. No século $X X$ durante o período da guerra-fria, nas décadas de 50, 60 e 70, os países desenvolvidos e em desenvolvimento voltaram a passar por um grande crescimento econômico, fato que levou a um novo e significativo aumento da demanda mundial por recursos hídricos destinados à: geração de energia hidrelétrica, irrigação, indústria e no abastecimento público nos grandes centros urbanos.

Para a geógrafa brasileira Bertha Becker (2003) a escassez de água é a mais recente preocupação, sendo percebida e anunciada como verdadeira catástrofe mundial, a ponto de lhe serem atribuído um valor estratégico similar ao do petróleo no século XX e a denominação de "ouro azul". Uma verdadeira hidropolítica se configura no cenário mundial.

Quem também corrobora com a idéia de uma hidropolítica para explicar o problema da "crise" mundial da água, é o geógrafo tunisiano Mohamed Bouguerra (2004), quando pergunta se existe uma escassez ou má gestão da água?

Outros geógrafos que também corroboram nas críticas a esse processo de valoração e mercantilização dos recursos naturais, em particular a água, são os professores da Universidade de São Paulo USP Wanderley Messias da Costa e Wagner Costa Ribeiro. Para eles esse discurso apocalíptico de uma "crise" mundial no abastecimento de água potável no século XXI, decorrente de uma próxima "escassez hídrica", defendido pelos neoclássicos, esconde o real interesse na apropriação privada da natureza, como capital natural, permitindo assim a sua mercantilização.
Para Costa (2003) essa escassez relativa (natural ou produzida), e a distribuição desigual têm transformado a água em um bem econômico crescentemente valorizado (commodity). Fato este agravado pelos desiguais níveis de acessibilidade entre povos e nações pobres e ricas à água de boa qualidade, acarretando sua maior valoração no mercado mundial, contradizendo o "direito universal à água" proclamado pela ONU.

Já para Ribeiro (2003) essa situação é ainda mais grave porque um dos temas que mais despertou interesse entre os presentes na Conferência Mundial da Água realizada em 2003 na cidade de Kyoto no Japão, foi o comércio da água doce. Comércio esse que já envolveria internacionalmente grandes grupos de capital privado, como as empresas francesas Vivendi e Suez, a alemã RWA, e a inglesa Thames Water.

É por isso que Costa (2003) afirma que a questão da desigualdade primária na distribuição dos recursos hídricos no mundo combinada à escassez relativa e dos níveis de acessibilidade a esses mesmos recursos constitui, atualmente, assuntos objeto da economia política, da geoeconomia e da geopolítica. Muito mais do que, propriamente, das ciências naturais (aí inseridas as ciências ambientais de extração exclusivamente ecológica).

Com base nos argumentos de Gleick (1993), Becker (2003), Costa (2003), Bouguerra (2004) e Ribeiro (2003 e 2008), ficam claro que o problema mundial da água doce, não está só na diminuição da disponibilidade absoluta (oferta menor que a demanda) em virtude do elevado crescimento demográfico, que leva à escassez hídrica, tão pouco ela deva ser regulada exclusivamente pelas leis do mercado. Mas sim na crise do 
desigual acesso à água, bem como nas diferentes formas de utilização e consumo, bem dispares entre os países ricos e pobres. Criando o que Becker chama de o paradoxo abundância do recurso versus inacessibilidade social, situação essa, muito bem explicada pela geografia política e pela geoeconomia.

Becker (2003) ainda é mais audaciosa a afirmar que o problema da escassez de água tem sido tratado como uma verdadeira catástrofe mundial no século XXI, e que a água doce terá a mesma importância econômica e militar que o petróleo teve no século XX. Ela fala ainda que uma verdadeira hidropolítica se configure no cenário mundial em relação ao "ouro azul".

Em outra obra mais recente Ribeiro (2008) escreve sobre uma "Geografia Política da Água" onde ressalta que instituições como a OMC e o Banco Mundial tem desempenhado uma função chave no processo de privatização dos serviços da água. O que tem levado a um verdadeiro comércio global da água.

Nesta mesma obra Ribeiro (2008) salienta que garantir o acesso à água para toda população do planeta é uma tarefa política, e que seria preciso estabelecer um acordo que possibilitasse a democratização do acesso à água.

\section{Metodologia utilizada}

Os dados levantados e abordados neste artigo fazem parte de um estudo maior desenvolvido pelo autor durante a realização do seu doutoramento na Universidade Federal do Pará entre os anos de 2002 a 2006. Onde na pesquisa realizada, foram levantados dados oficiais juntos aos relatórios oficiais da ONU, e de ONGs, bem como através de uma profunda pesquisa bibliográfica sobre o tema na geografia e em áreas afins, como na Geografia Política. Para tanto, foi de fundamental importância o levantamento documental realizado nos sítios oficiais de Organizações Governamentais e em Universidades de outros países.

\section{Resultados: Que "crise” mundial da água é essa?}

A "crise" da água doce no mundo se faz presente de duas formas, uma que envolve a quantidade suficiente de água doce, seja as superficiais contidas nas bacias hidrográficas, ou as subterrâneas armazenadas nos aqüíferos ou precipitas na forma de chuva, e a sua qualidade em relação aos desejáveis parâmetros físicos, químicos e bacteriológicos, que permitam um potencial (oferta) disponibilidade hídrica para atenderem as reais demandas atuais e futuras em relação às diferentes formas de uso, rural, doméstico e industrial.

Segundo o WWAP (2003): “Por crisis del agua se entiende la falta, actualmente crônica y muy extendida, de suministros de agua potable de buena calidad y precio razoable y de servicios de saneamiento, junto a la elevada incidencia de enfermedades ligadas, la destrucción del agua de ríos y lagos".

Essa interpretação apresentada pela ONU sobre a "crise" mundial da água doce, esta diretamente relacionada às diferentes formas de apropriação, uso e conservação dos recursos hídricos, por parte da população dos países desenvolvidos, em desenvolvimento e subdesenvolvidos, onde a questão principal é a desigual oferta entre esses países, do abastecimento de água potável de boa qualidade a preços razoáveis, 
e dos serviços de saneamento, fundamentais à melhoria da qualidade de vida dessas populações.

A "crise" que envolve o atendimento ao aumento mundial do consumo de água potável, no caso, a crescente demanda por água em boa quantidade e qualidade, destinada aos usos agrícola, industrial e doméstico, relaciona-se não só à distribuição espacial e temporal desse recurso, mas à capacidade de atender a essas diferentes demandas com custo razoável e sem conflitos. (ver figura 01)
Mas, se por um lado nos deparamos com situações de abundância no abastecimento de água para esses fins, na grande maioria dos países desenvolvidos, o mesmo não se pode afirmar em relação aos países em desenvolvimento e, principalmente, aos subdesenvolvidos, visto que, na sua grande totalidade, o atendimento dessa demanda ainda é muito precário, ou mesmo ausente, caracterizando assim uma grande escassez hídrica.

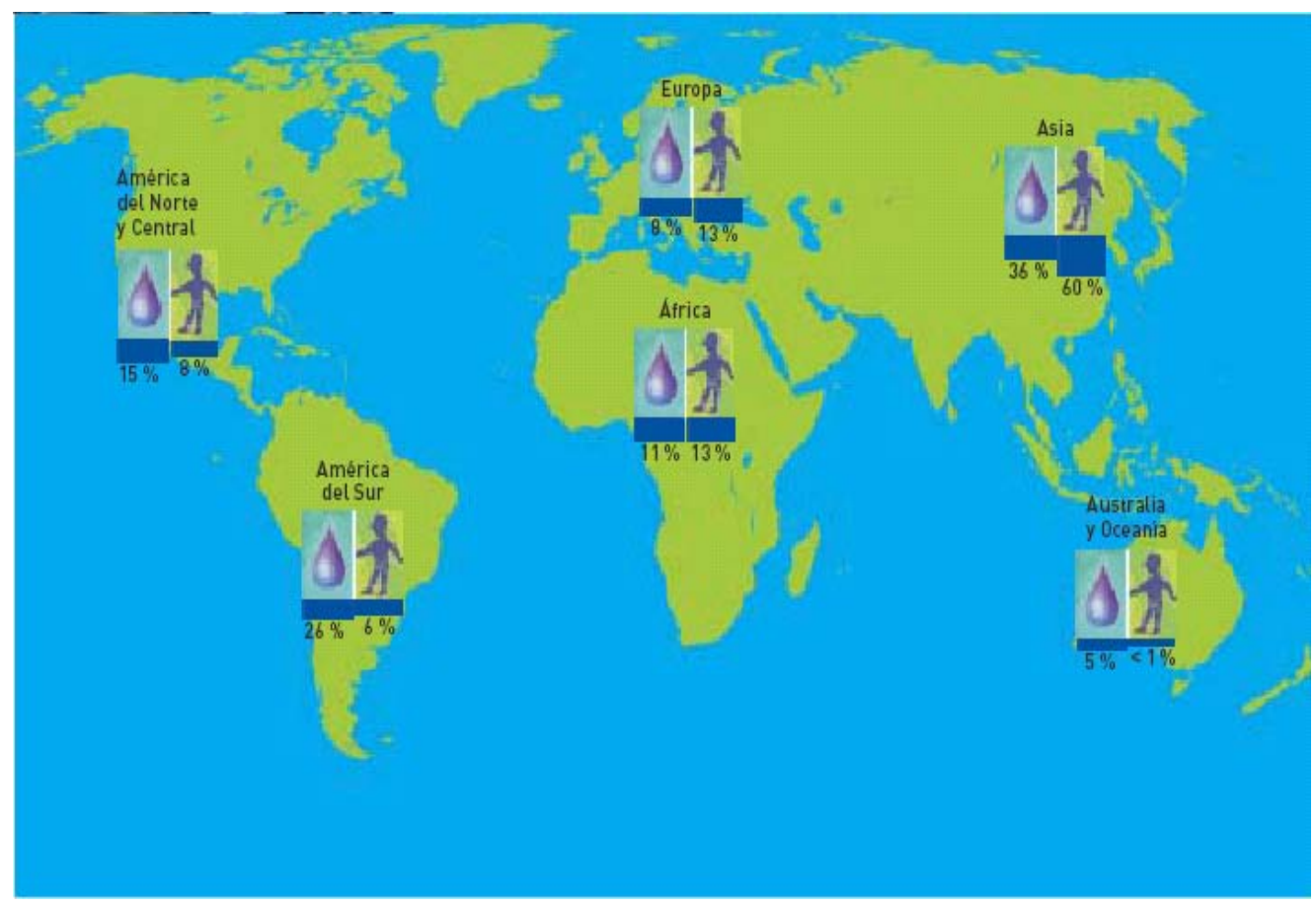

Figura 01 - Mapa da distribuição de água doce no mundo (WWDR/ ONU, 2003)

Os dados divulgados no relatório da ONU (WWDR, 2003), mostram bem essas desigualdades entre os países desenvolvidos, os em desenvolvimento e os subdesenvolvidos. Quanto aos usos alternativos da água nos países desenvolvidos, o uso industrial é o mais representativo com 59\%, seguido do agrícola com $30 \%$, e o restante $11 \%$ destinado ao doméstico. Já nos países em desenvolvimento e subdesenvolvidos, os números mostram que a maior parte do uso da água, $82 \%$ é destinada à agricultura, $10 \%$ para o uso industrial e somente $8 \%$ para o uso doméstico. 
Em relação aos dados sobre 0 percentual da população mundial, dividida por continentes, que ainda não possuem serviços de distribuição e abastecimento de água potável e a rede de saneamento, as desigualdades ainda são maiores.

Para a população mundial que ainda não possui serviços de abastecimento de água potável, a Ásia lidera com 65\%, em seguida a África com 27\%, a América Latina e o Caribe com 6\%, e a Europa com somente $2 \%$. Quanto à população mundial que não é atendida pelos serviços de saneamento, os dados mostram mais uma vez que a Ásia lidera com $80 \%$, seguida pela África com $13 \%$, a América Latina e o Caribe com 5\% e a Europa novamente, com apenas 2\%. É bom salientar, que nas duas pesquisas não aparecem os Estados Unidos e Canadá, pois esses serviços atendem a totalidade da população. (ver figura 02).

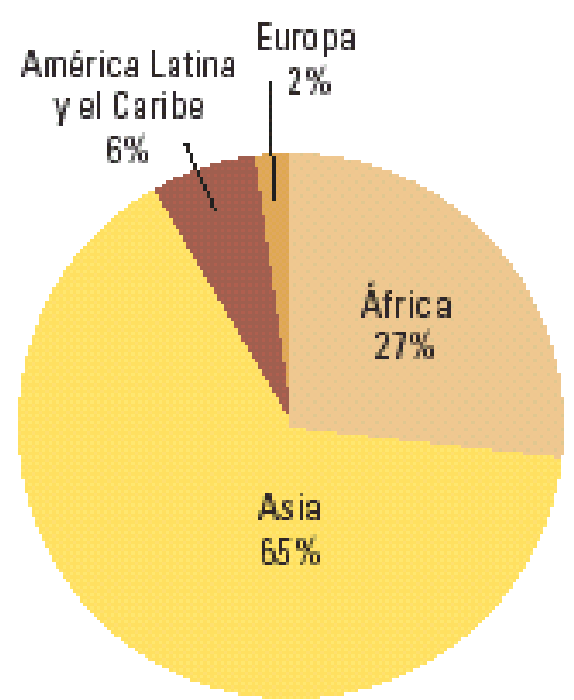

Abastecimiento de agua, distribución de poblaciones sin servicio

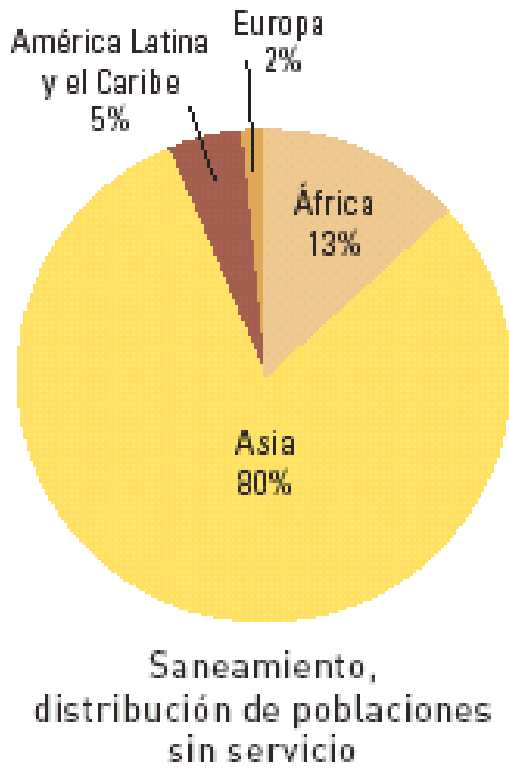

Figura 02 - População mundial sem serviço de abastecimento deágua e saneamento (WWDR/ ONU, 2003)

Diante de tal situação, vem ocorrendo a busca cada vez maior de novas fontes de recursos hídricos em boa quantidade e qualidade, passando a ser uma das grandes preocupações dos países em desenvolvimento e os subdesenvolvidos, que possuem escassez hídrica. Contudo, a origem do problema não se encontra apenas no fato desses países obterem uma maior quantidade de água doce, e de fácil captação, como as águas superficiais, disponibilizada nas bacias hidrográficas.

El consumo de agua per cápita aumenta (debido a la mejora de los niveles de vida), la población crece y en consecuencia el porcentaje de agua objeto de apropiación se eleva. $\mathrm{Si}$ se suman las variaciones espaciales y temporales del agua disponible, se puede decir que la cantidad de agua existente para todos los usos está comenzando a escasear y ello nos lleva a una crisis del agua. (WWDR/UNESCO/ONU, 2003, p. 9). 
Mas a necessidade de se adequar à oferta disponível desse recurso, as formas de usos que priorizem a melhoria das condições de saneamento urbano e rural, a irrigação das áreas agrícolas, geração de energia, indústria, e outras que garantam a melhoria da qualidade de vida da grande maioria da população pobre, que sofre com a escassez hídrica.

El estado de pobreza de un amplio porcentaje de la población mundial es a la vez un síntoma y una causa de la crisis del agua. El hecho de facilitar a los pobres un mejor acceso a una agua mejor gestionada puede contribuir a la erradicación de la pobreza. Al mismo tiempo, una mejor gestión nos permitirá hacer frente a la creciente escasez de agua per cápita en muchas partes del mundo en desarrollo. (WWDR/UNESCO/ONU, 2003, p. 4)

As dificuldades apresentadas pelos países subdesenvolvidos em relação à gestão dos seus recursos hídricos estão relacionadas aos graves problemas econômicos e sociais, que dificultam a adoção de políticas públicas eficazes no tratamento de questões, como a melhoria da infra-estrutura do saneamento urbano e rural, através de obras de ampliação do sistema de abastecimento de água potável e da rede de esgoto sanitário, irrigação de áreas agrícolas e geração de energia hidráulica, que são vitais ao processo de desenvolvimento econômico e social. Essa preocupação está muito presente nos onze desafios, frente à vida e o bem estar, apresentado no relatório do WWDR/2003:

1 - Satisfacer las necesidades humanas básicas;

2 - Proteger los ecosistemas en bien de la población;
3 - Ciudades: necesidades divergentes del entorno urbano;

4 - Asegurar el suministro de alimento para una población mundial creciente;

5 - Promover una industria más limpia en beneficio de todos;

6 - Utilizar la energía para cubrir las necesidades del desarrollo;

7 - Reducir los riesgos y hacer frente a la incertidumbre;

8 - Compartir el agua: definir el interés común;

9 - Identificar y valorar las múltiples facetas del agua;

10 - Asegurar la difusión de los conocimientos básicos: una responsabilidad colectiva;

11 - Administrar el agua de modo responsable para asegurar un desarrollo sostenible.

Esses desafios mostram bem uma clara preocupação por parte da ONU, em relação à gestão dos recursos hídricos mundiais, para a segunda metade deste século, diante dos indicadores de mau uso, desperdício e poluição.

A "crise" da água, então, passa a ser concebida como um problema muito mais de gestão e governabilidade, do que, essencialmente, a escassez do recurso. A proposta de gestão dos recursos hídricos, de forma integrada, participativa, e descentralizada, através de políticas públicas que priorizem, a aplicação de leis e instrumentos que regulem as diferentes formas de apropriação, uso e poluição, surge como principal mecanismo de regulação entre o estado e a sociedade, capaz de fato de evitar os riscos de escassez hídrica.

Para Bouguerra (2004) essa "crise" da água prevista pela ONU para o início do 
século $X X I$, só terá sentido se a gestão, o consumo e os recursos de água não se alterarem.

Caberá então, aos países que desejam superar suas crises de água, a implantação de formas de gestão, que permitam uma melhor governabilidade do estado em conjunto com a sociedade, através de ações negociadas e transparentes, capazes de permitir um desenvolvimento sustentável dos seus recursos hídricos.

Mas para Gleick (1998) ainda não existe um "risco" de escassez hídrica para o século XXI em algumas regiões do planeta. Pois o problema não esta relacionado à diminuição da oferta de água, visto que o volume disponível para a captação/exploração ainda é muito maior que a demanda atual. O "risco" não estaria na oferta de água, mas na manutenção do tradicional modelo de planejamento do abastecimento de água para os diversos fins (irrigação, indústria, hidrelétrica, abastecimento público, etc) em virtude de se preocupar apenas com o fornecimento contínuo e cada vez maior do volume de água, mesmo que a fonte esteja cada vez mais distante e cara do seu local de uso.

$$
\text { Esse modelo tradicional }
$$

caracterizado na busca de novos e maiores mananciais (grandes represas), localizados em regiões cada vez mais distantes, onde a água é transportada via longos canais artificiais ou aquedutos, já estaria sendo substituído nos EUA desde a década de 1990 por um novo paradigma.

Este paradigma se orienta no sentido de uso mais sustentável do recurso hídrico. Ao invés da busca cada vez mais distante e cara, por novos mananciais localizadas em outras bacias hidrográficas com grande disponibilidade hídrica, seria melhor e mais barato, o investimento no aumento da eficiência dos sistemas de: captação, tratamento e distribuição da água para os diversos fins. Essa eficiência esta relacionada à melhoria tecnológica dos sistemas e equipamentos utilizados nas redes de abastecimento, que precisam ter um menor desperdício de água que ocorre nos vazamentos e defeitos da rede.

A outra forma apontada por Gleick (1998) como eficiência no sistema, é o fato de cada vez mais os consumidores norteamericanos se preocuparem em construírem suas casas e apartamentos, onde nas cozinhas e banheiros as torneiras, duchas, chuveiros e os vasos sanitários, sejam cada vez mais eficientes ao consumirem ou desperdiçarem uma quantidade cada vez menor de água tratada.

Essa preocupação com a maior eficiência e menor desperdício não esta só nos moradores das cidades, mas também nos fazendeiros que passam a utilizar sistemas de irrigação mais eficazes e econômicos, como também nas indústrias que foram obrigadas a combater o desperdício de água tratada e no tratamento dos seus efluentes líquidos que reciclados voltaram à rede local.

Essa preocupação com a superação dos riscos de "crise" mundial no abastecimento de água doce requer uma maior regulação dos conflitos entre os usuários (países/estados/municípios) públicos e privados dos recursos hídricos, com a implementação de políticas públicas voltadas para gestão dos recursos hídricos, garantindo uma governabilidade no acesso, uso e proteção desse precioso bem indispensável à sobrevivência pacífica da humanidade. 
A forma como algumas instituições e pesquisadores internacionais, apresenta um cenário de "crise" na demanda por água doce (escassez hídrica) que afetaria a sobrevivência da humanidade, principalmente nos países subdesenvolvidos, na segunda metade do século XXI, é também criticada pela geógrafa brasileira Bertha Becker e professora da UFRJ, ao defender que essa visão global apocalíptica e catastrófica está relacionada a uma previsão de um "explosivo crescimento demográfico" defendido sob uma nova roupagem, pelas teses malthusianas.

Outra grande crítica a esse discurso neomalthusiano sobre o significativo aumento da demanda pela água nos países em desenvolvimento vem da ativista indiana Vandana Shiva no seu livro "Guerra por Água" (2006), quando defende que o declínio do abastecimento não resulta apenas do aumento populacional, mas é agravado também pelo uso excessivo da água. Para Shiva a cultura ocidental moldada pelos valores altamente materialistas e consumistas das sociedades urbanas e industriais, tem convertido a abundância em escassez da água.

Nas interpretações dos dados demográficos referentes ao crescimento populacional, e o das grandes cidades, são desconsideradas as possibilidades de haver uma diminuição nas taxas de crescimento populacional e urbano, como fora verificado nas últimas décadas nos países desenvolvidos e em desenvolvimento.

O simples crescimento populacional de um país, junto com o seu crescimento urbano, não é indicador suficiente que possa garantir que todos os habitantes terão acesso aos mesmos serviços de abastecimento de água potável e coleta e tratamento de esgoto sanitário. Bem como o calculo médio do consumo de água por habitante (m3/hab/dia) de um país ou de uma cidade, não reflete o real consumo doméstico numa sociedade marcada por grandes desigualdades sociais e econômicas, que refletem diretamente no poder aquisitivo e no seu bem estar.

Culpar o crescimento demográfico e o desenvolvimento pelas mazelas do mundo constitui uma falácia. Primeiro, porque não se pode afirmar que o crescimento continuará seguindo as taxas que apresentou no século XX. Apesar do "fenomenal" crescimento demográfico nos últimos cinqüenta anos - 2,5 bilhões de indivíduos em 1950, 5 bilhões em 1990 e 6 bilhões em 2000 -, os próprios demógrafos prevêem uma inflexão nesse processo, com um total de 8 - 9 bilhões em 2025 e uma estabilização entre 9 - 12 bilhões por volta de 2050 (Le Moigne et TernièreBuchot, 1998). Isto se a inflexão não for maior. Segundo, já há décadas foi demonstrado que, ao contrario, o desenvolvimento reduz o crescimento demográfico, (BECKER, 2003. IN: ARAGÓN, \& CLUSENER-GODT, 2003, p. 279).

Segundo os dados da própria ONU (2003), as atividades agrícolas correspondem cerca de $70 \%$ do consumo mundial de água doce no planeta, sendo ainda maior nos países subdesenvolvidos e em desenvolvimento, com $82 \%$. Esse quadro, aliado ao problema da inacessibilidade da grande maioria da população de baixa renda desses países aos serviços de abastecimento de água potável (65\% Ásia, 27\% África e 6\% América Latina), mostram que são falsas e exageradas as premissas demográficas, que responsabilizam o crescimento populacional e urbano, como os grandes vilões do consumo e desperdício de água.

Outro grande fator desconsiderado pelos neomalthusianos é a capacidade do 
estado e da própria sociedade urbana, implementarem medidas de controle no abastecimento e uso da água potável, e medidas voltadas ao combate do desperdício, através de métodos educativos e punitivos. Essas ações estão presentes nos programas de gestão dos recursos hídricos, permitem um efetivo controle sobre a apropriação, uso e proteção das águas evitando assim sua eminente escassez. Logo tentar restringir a responsabilidade pela e escassez de água doce no planeta, a fatores demográficos, criando um cenário apocalíptico, representa uma visão reducionista e quantitativa do problema, visto que, a situação requer também uma análise de caráter sócio, econômico, político e ambiental a nível mundial e regional, bem como a adoção de políticas públicas voltadas para gestão dos recursos hídricos.

No caso mais específico do recurso água, Becker (2003) relata ainda que essa tentativa de mercantilização da natureza esta bem presente nas diretrizes do Banco Mundial ao atribuir um valor de mercado a água. Como sendo a única forma de combater o seu desperdício e a escassez, visto que, na grande maioria dos países periféricos, principalmente em relação aos países muçulmanos, a água é tida como um bem gratuito.

Essa mercantilização da água, sustentada pelas teses da economia ambiental neoclássica, outrora adotada pelo Banco Mundial, encontra-se segundo Becker (2003), presente nas seguintes propostas: implantação de um sistema de taxas sobre o uso, a predação e os rejeitos; na criação dos mercados de BOT (Build, Operate and Transfer); e com a implantação do mercado dos direitos da água, onde o próprio mercado e não o estado será o responsável pela determinação do preço e da quantidade de água alocada, experiência esta já adotada recentemente nos EUA e no Chile.

Esse debate político esteve bem visível nas três últimos Fóruns Mundial da Água FMA (Kyoto, 2003; Cidade do México, 2006 e Istambul, 2009) onde foram travadas guerras de paradigmas da água como direito humano ou água como mercadoria. No 4 으 FMA (WWF) realizado na Cidade do México em Março de 2006, o Ministro da Água na Bolívia foi enfático na sua declaração:

"Hacemos nuestras las palabras del Comité de Derechos Económicos Sociales y Culturales (CDESC) de las Naciones Unidas de Noviembre del 2.002 que señalan: “El agua es una riqueza natural limitada y un bien público fundamental para la vida y la salud. El derecho humano al agua es indispensable para poder vivir una vida con dignidad humana. Es un pre requisito para la realización de otros derechos humanos."

E durante o 5 FMA (WWF) realizado em Março de 2009 na cidade de Istambul, o debate voltou à sena com mais vigor, sedo que agora as autoridades brasileiras manifestaram-se contrários ao acesso à água como um direito universal, posição esta criticada por vários países, principalmente os seus vizinhos da América do sul.

O fato de o Brasil, ao lado de Estados Unidos, Egito e Turquia, não reconhecer o acesso à água como um direito humano básico causou certo mal-estar no 5o Fórum Mundial da Água, realizado esta semana em Istambul. (...) Vários países da América Latina, como Bolívia, Equador, Venezuela, Cuba e Uruguai, além de Suíça e Espanha, se mostraram descontentes com a posição dos brasileiros, que estariam se negando a debater 0 assunto. Fonte: Matéria da Agência EFE, no 
www.estadao.com.br, quinta-feira, 19 de março de 2009. Acessado em 21/03/2009.

Petrella (2004) também argumenta que neste século a água suscitará três grandes questões, que envolvem todos os habitantes e as sociedades do mundo.

$1^{\circ}$ ) O acesso à água potável é um direito humano, por isso universal, indivisível e imprescritível, ou uma necessidade vital cuja satisfação passa através dos mecanismos de mercado?

$2^{\circ}$ ) A quem pertence à água? Trata-se de um bem comum (comum a quem, a que tipos de comunidades), ou trata-se de um bem apropriável, a título privado, de uma mercadoria vendável que podemos comprar como petróleo ou outro bem/mercadoria?

$\left.3^{\circ}\right)$ É possível deter os processos de rarefação e de escassez crescente dos recursos hídricos do Planeta, garantindo a utilização das águas e a segurança de abastecimento para todos, segundo os princípios de uma gestão sustentável e solidária, ou devemos deixar a escolha, quanto à locação dos recursos hídricos do Planeta, às lógicas geopolíticas dos estados nacionais e às lógicas financeiras dos detentores privados de capital, enfraquecendo, assim, as formas e as práticas de democracia representativa e participativa?

Essa tarefa política em se analisar o debate político sobre o acesso e o controle da água, se confunde com o que entendemos ser uma verdadeira hidropolítca global, bem expressa tanto na geografia política, quanto na ecologia política.

Considerações finais

Ter o direito de livre acesso à água, mas acima de tudo em níveis de elevada qualidade, deixou de ser apenas uma reivindicação da população pobre localizada na zona rural. Mas também dos milhões de habitantes das favelas das grandes cidades, que ainda não são atendidos pelos serviços da água.

Resolver o problema da falta e da má qualidade dos serviços da água a esta parcela da população mundial rural e urbana, não é apenas uma questão de ordem econômica e tão pouco de mercado. Uma vez que o abastecimento de água à população não deve ser visto apenas como um serviço.

No final do século $X X$ instituições como a OMC e o Banco Mundial defenderam que 0 aumento dos sistemas de abastecimento de água nos países em desenvolvimento, não deveriam mais ficar sob a responsabilidade das empresas públicas. E que o aumento da demanda pelos serviços da água só poderiam ser atendidos por empresas privadas, tidas como as únicas capazes de ampliar com qualidade e rapidez esses serviços. O que acarretou numa verdadeira onda de privatização das Companhias Públicas por todo o mundo.

E aqui a água se apresenta de fato como "ouro azul" disputado e pretendido por todos, pelos que a vêem como um bem apropriável, a título privado, de uma mercadoria vendável, versus os que defendem que o acesso à água potável é um direito humano, por isso universal, indivisível e imprescritível.

O mais grave é que este cobiçado "ouro azul" vem sendo cada vez mais disputado em grandes conflitos mundiais, regionais e/ou locais, gerando verdadeiras batalhas ou guerras por água, na Ásia, Oriente Médio, África, América Latina e até nos EUA. 
A água não pode ser entendida aqui como apenas mais um recurso natural transformado em mercadoria outrora defendido pelas teses do neoliberalismo econômico. Ela deve ser sim aceita e compreendida como um bem de direito universal a todos, tendo mais do que apenas um valor econômico, mas um valor simbólico, espiritual, sanitário, cultural, alimentar e de saúde pública. A água deve ser tratada como um "Patrimônio da Humanidade", sem restrição de acesso a todos os povos.

\section{Referências bibliográficas}

BARLOW, M \& CLARK, T. Ouro azul. Como as grandes corporações estão se apoderando da água doce do nosso planeta. São Paulo: Ed M. Books, 2003.

BECKER, B. Inserção da Amazônia na geopolítica da água. In: ARAGÓN, L. E \& CLUSENER-GODT, M. (orgs.) Problemática do uso local e global da água da Amazônia. Belém: NAEA/UFPA/UNESCO. 2003.

BORDALO, C. O Desafio das Águas numa Metrópole Amazônida. Uma reflexão das Políticas de Proteção dos Mananciais da Região Metropolitana de Belém - PA (1984 2004). Tese de Doutorado. NAEA/UFPA. Belém. 2006.

BOUGUERRA, M. L. As batalhas da água. Por um bem comum da humanidade. Ed Vozes. Petrópolis, 2004.

CLARKE, R \& KING, J. O Atlas da Água. O mapeamento completo do recurso mais precioso do planeta. Ed Publifolha. São Paulo. 2005.

COSTA, W. Geografia Política e Geopolítica. Edusp. São Paulo. 2008.

- Valorizar a água da Amazônia: Uma estratégia de inserção nacional e internacional. In: ARAGÓN, L. E \& CLUSENER-GODT, M (orgs.) Problemática do uso local e global da água da Amazônia. Belém: NAEA/UFPA/UNESCO. 2003.
GLEICK, P. H. The World's Water. 1998 1999. The Biennial Report on Freshwater Resources. Island Press. Washington. 1998.

ORGANIZACIÓN DE LAS NACIONES UNIDAS. Programa Mundial de Evaluación de los Recursos Hídricos - ONU/WWAP. Coloquemos las piezas Juntos. El Programa Mundial de Evaluación de los Recursos Hídricos. Al servicio del desarrollo, el

fortalecimiento de capacidades y el medio ambiente. Paris, 2001. - agua para todos agua para VIDA. Informe de las Naciones Unidas sobre el Desarrollo de los Recursos Hídricos en el Mundo. Paris, 2003.

PETRELLA, R. A água. O desafio do bem comum. In: NEUTZLING, I (org). Água: bem público universal. Coleção Humanitas. São Leopoldo: Ed Unisinos. 2004. . O Manifesto da Água. Argumentos para um contrato mundial. Petrópolis: Ed Vozes. 2002.

RIBEIRO, W. Geografia Política da Água. São Paulo: Editora Annablume. 2008. Água Doce: Conflitos e Segurança Ambiental. In: MARTINS, R. C \& 
VALENCIO, N. F (orgs.) Uso e Gestão dos Recursos Hídricos no Brasil. Desafios Teóricos e Políticos-Institucionais. São Carlos: Ed Rima, v II. 2003.

SHIVA, V. Guerra por água. Privatização, poluição e lucro. Ed Radical livros. São Paulo. 2006. 